\title{
Flow Characteristics and Cavitation Effect of the Submerged Water Jet Discharged from a Central-Body Nozzle
}

\author{
Haixia Liu', Qiming Shao1, Can Kang² \\ ${ }^{1}$ School of Material Science and Engineering, Jiangsu University, Zhenjiang, China \\ ${ }^{2}$ School of Energy and Power Engineering, Jiangsu University, Zhenjiang, China \\ Email: lhx@ujs.edu.cn
}

Received 17 August 2014; revised 3 September 2014; accepted 7 October 2014

Academic Editor: Junhui Li, Central South University, China

Copyright (C) 2014 by authors and Scientific Research Publishing Inc.

This work is licensed under the Creative Commons Attribution International License (CC BY). http://creativecommons.org/licenses/by/4.0/

(c) (i) Open Access

\section{Abstract}

To assess the impingement capability of water jet, submerged water jet discharged from a central-body nozzle is investigated. Efforts are devoted to both the wavy jet edge and the cavitation phenomenon involved. Three configurations of the central body are examined and jet pressure is fixed at $15 \mathrm{MPa}$. Jet edge is visualized using high speed photography. Numerical simulation is performed to extract flow parameter distributions in the jet stream and to predict cavity profiles. Furthermore, an impingement experiment with target sandstone samples is conducted as well. The results indicate that both lateral fluctuation amplitude and frequency of the jet stream vary with axial position of the central body. Cavitation tongues of different stream wise dimensions are manifested in the wake flows downstream of the central body. In case of the downstream end of the central body parallel with nozzle outlet section, the largest stream wise dimension of cavitation zone is obtained. Relative to the round nozzle with the same equivalent outlet diameter, the central-body nozzle yields preferable impinging effect.

\section{Keywords}

Submerged Water Jet, Cavitation, Numerical Simulation, Impingement

\section{Introduction}

The concept of the central-body nozzle was introduced in 1980s, and this kind of nozzle was used firstly in mining industry [1]. As high-pressure liquid moves around a blunt-ended central body fixed inside the flow passage of the nozzle, low-pressure zone might appear immediately downstream of the blunt end, which might 
spur the occurrence of cavitation. Erosion of solid surface will be accelerated provided that cavitation bubbles collapse near the target surface [2]. However, detailed mechanisms underlying such kind of cavitation have rarely been reported. Additionally, quantitative examination of cavitation erosion effect necessitates feasible techniques. Furthermore, the shear layer generated between high-velocity water emanating from a central-body nozzle and ambient water also contributes to the onset of cavitation.

For submerged water jet, flow patterns near the nozzle depend on both nozzle outlet shape and jet pressure [3]. Meanwhile, intense momentum transfer arises between the jet flow and ambient water, which leads to the disturbance on jet edge and the dissipation of jet kinetic energy. The position of cavitation zone and wake flow characteristics play an important role in the determination of optimal operation parameters such as standoff distance and the angle between sample surface and jet axis [4]. At present, for submerged water jet, measurement of flow parameter distributions is difficult, particularly at high jet pressure [5]. And the visualization of cavitation phenomena near the nozzle is also problematic in this context [6].

Here, with a thin cylinder intruding into the flow passage of a round nozzle, submerged water jet discharged from a central-body nozzle at jet pressure of $15 \mathrm{MPa}$ is investigated. High speed photography is employed to capture instantaneous fluctuations of jet edge near nozzle outlet. Numerical simulationis conducted to verify cavitation effect downstream of the central body. An impingement experiment is carried out to assess the erosion capacity of submerged water jet. It is expected to provide an in-depth demonstration of features of the centralbody nozzle and cast light upon cavitation phenomenon in submerged water jet.

\section{Experimental Set-Up}

As shown in Figure 1, an experimental system was constructed for studying both flow characteristics and erosion capability of submerged water jet. Acylinder central-body is fixed with its axis collinear with the symmetrical axis of the flow passage of the nozzle. Figure 2 schematically shows across section of the nozzle. The axial distance, $s$, is defined as the indent distance of the central body in the flow passage. Three schemes are accomplished as $s$ is set to $0.0 \mathrm{~mm}, 0.5 \mathrm{~mm}$ and $1.0 \mathrm{~mm}$. It is conceivable that both the wake flow downstream of the central body and cavitation phenomenon are affected by such an indent distance.

\section{Fluctuation of Jet Edge near the Nozzle}

According to statistical results based upon water jets at jet pressures larger than $10 \mathrm{MPa}$, unsteady characteristics are evident represented by transient variation of flow parameters and the interaction between jet and ambient medium [7] [8]. Thus it is unambiguous for submerged water jet that jet edge fluctuation undergoes large ambient water resistance and diversified flow phenomena occur.

Three nozzles corresponding to the three values of $s$ were manufactured and jet pressure of $15 \mathrm{MPa}$ was adopted in the visualization experiment. High speed photography allows for a close observation of jet edge [9]. Parallel to some practical applications of water jet, the jet segment within the stream wise distance of $10.0 \mathrm{~mm}$ from the nozzle outlet section was focused. The image-recording frequency was set to $5000 \mathrm{fps}$. An LED light of $100 \mathrm{~W}$ was used as the auxiliary light source. Image-taking was performed as water jet became fully developed.

Instantaneous variation of jet edge with sampling time is presented in Figure 3 where the time interval between every two adjacent images is $0.2 \mathrm{~ms}$. At $s=0.0 \mathrm{~mm}$, cross-section width of the jet stream is large compared with the other two conditions. While in Figure 3(b) and Figure 3(c), variations of jet width are analogous. A further demonstration of the similitude and difference of the three schemes is depicted in Figure 4 where the monitored cross-section is $3.0 \mathrm{~mm}$ away from nozzle outlet section.

It is shown in Figure 4 that cross-section width of the jet stream at $s=0.0 \mathrm{~mm}$ remains the largest for all the sampling period. However, the corresponding fluctuation magnitudes are much lower than those associated with the other two schemes. At $s=0.5 \mathrm{~mm}$ and $s=1.0 \mathrm{~mm}$, fluctuation features are similar, and the fluctuation frequencies agree well with each other.

\section{Numerical Simulation}

With existing flow visualization techniques, it is questionable to discern jet stream in obtained images under submerged conditions. Numerical simulation was utilized to depict complex flows downstream of nozzle outlet. 


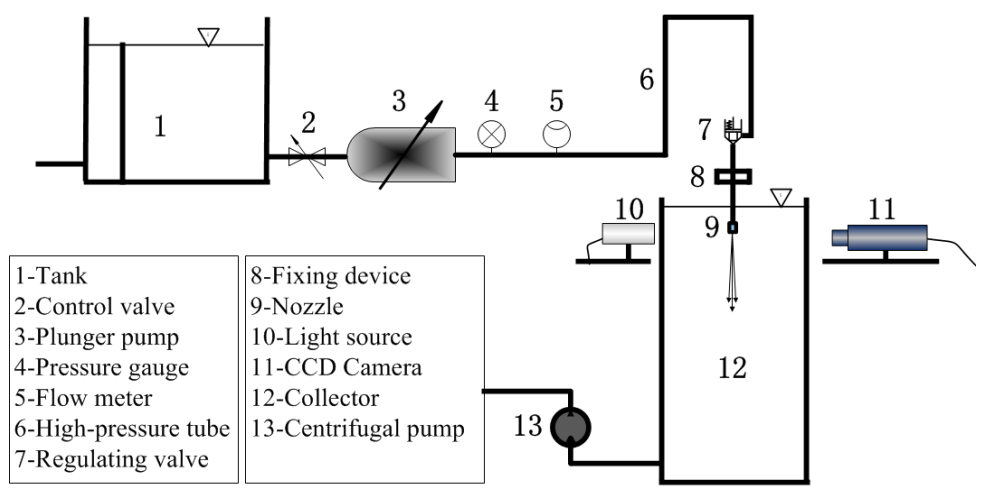

Figure 1. Sketch of the experimentalsystem for submerged water jet.

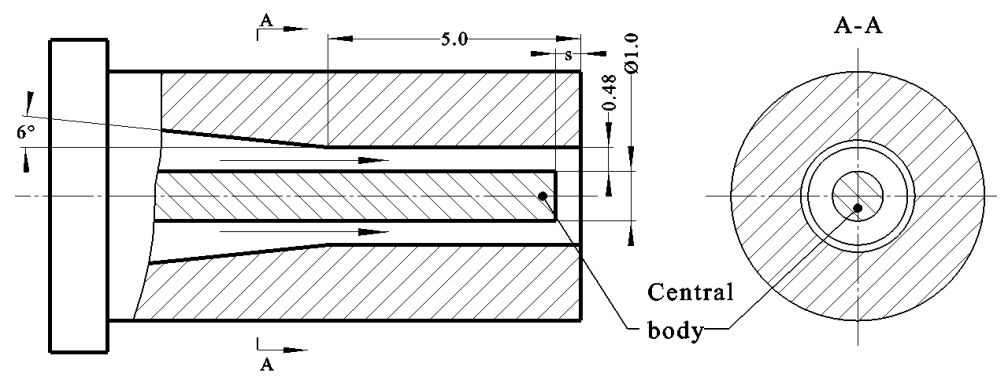

Figure 2. Cross-sectional view of the central-body nozzle.
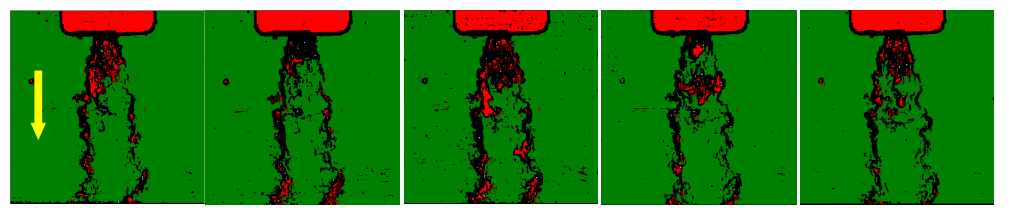

(a)
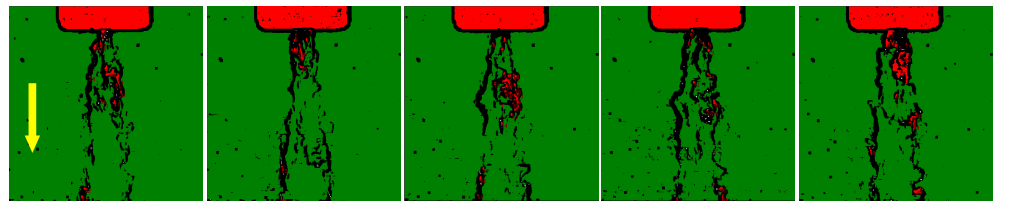

(b)
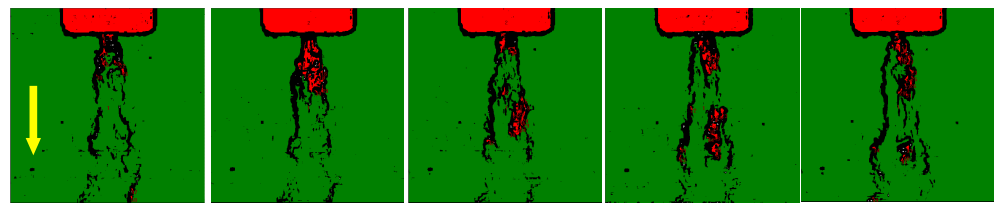

(c)

Figure 3. Jet edge fluctuations at different indent distances. (a) $s=0.0 \mathrm{~mm}$; (b) $s=0.5 \mathrm{~mm}$; (c) $s=1.0 \mathrm{~mm}$.

It should be noted that a comparison can be implemented between steady numerical results and statistical experimental results $[10]$.

\subsection{Computational Zone}

According to the axially symmetrical assumption of the water jet, one-quarter of the entire computational zone is devoted to simulation. In Figure 5, a cubic computational zone including water jet flow and ambient water is 


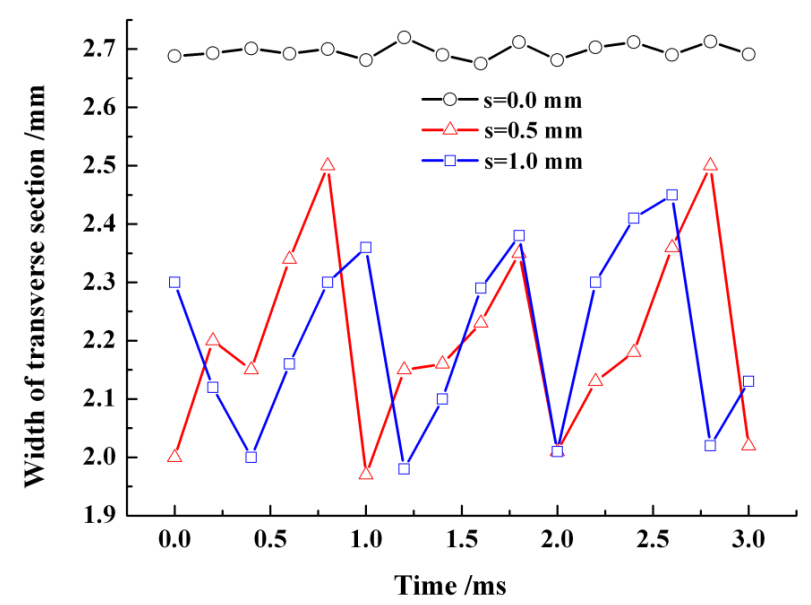

Figure 4. Variation of jet width on the cross-section $3.0 \mathrm{~mm}$ away from nozzle outlet section.

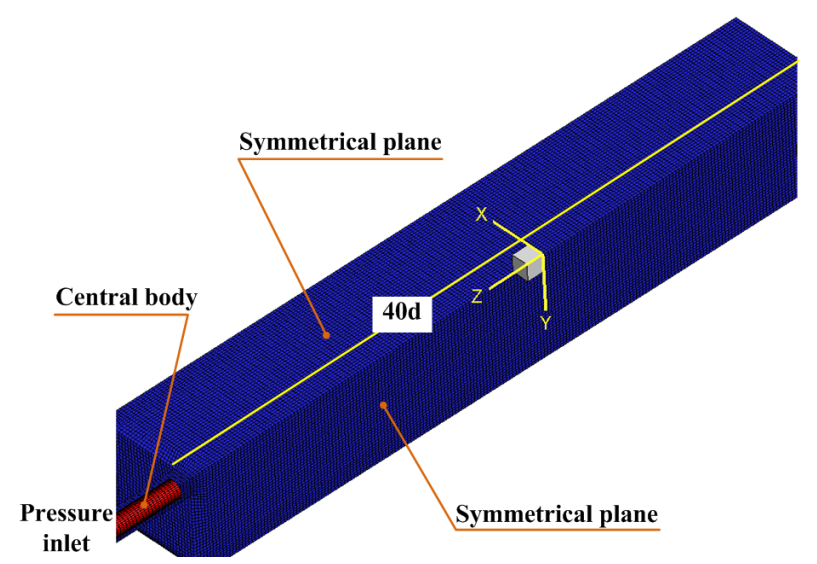

Figure 5. One-quarter of the entire jet flow zone.

presented. The stream wise length of the computation zone is $40 d$ where $d$ is the outlet diameter of the nozzle outlet section. And the transverse dimensions of the computational zone are $20 d \times 20 d$. The total gird number at $s=0.0 \mathrm{~mm}$ is $1,273,705$.

\subsection{Turbulence Model}

Based on Reynolds averaged Navier-Stokes (RANS) equations and RNG (Renormalization group) $k-\varepsilon$ turbulent model, three-dimensional steady and unsteady computations were carried out. Scalable wall function was applied to deal with flows near all solid walls. Velocity-pressure coupling was accomplished automatically with the ANSYS-CFX solver used.

\subsection{Cavitation Model}

The Rayleigh Plesset model was used to model the inception and evolution of cavitation in the computational zone. Relative to other cavitation models, this model is advantageous in terms of modeling cavitation inception and bubble collapse [11]. And the primary and second phases were set to be water and vapor, respectively. The mean nucleation site diameter was set to be $2 \times 10^{-6} \mathrm{~m}$. Cavitation condensation and vaporization coefficients were set to be 0.01 and 50 , respectively. Volume fraction of the nucleation sites was set to be $5 \mathrm{e}^{-4}$.

\subsection{Boundary Conditions}

Non-slip boundary condition was set at all solid walls. Uniform pressure distribution was set at the nozzle inlet 
section. And pressure outlet condition was applied for all outlet sections of the computational zone.

\subsection{Results and Discussion}

\subsubsection{Velocity Distribution}

Dissipation of stream wise velocity along the jet axis is plotted in Figure 6. The maximum velocity occurs at $s=$ $1.0 \mathrm{~mm}$. At $s=0.0 \mathrm{~mm}$, the peak velocity is the minimum among the three schemes and the stream wise position corresponding to the velocity peak is approximately $6.0 \mathrm{~mm}$ away from the nozzle outlet section. A velocity valley is seen in each velocity curve, but corresponding stream wise positions are different. Water discharged from the annulus section around the central body concentrates towards a point on the jet axis. And then the water jet reconstructs itself downstream of such a point. Nevertheless, the position of such a point varies with the indent distance of the central body, which apparently gives rise to different starting points of reorganized water jets.

As shown in Figure 7, three cross sections with axial distances of $1.0 \mathrm{~mm}, 3.0 \mathrm{~mm}$ and $5.0 \mathrm{~mm}$ from the nozzle outlet section are extracted for a demonstration of distributions of velocity and volume fraction of cavitation phase. The three schemes are similar in that a velocity valley is presented near the jet axis. Nevertheless, the most explicit valley is associated with the scheme of $s=0.0 \mathrm{~mm}$. In addition, the maximum velocity magnitude at $s=0.0 \mathrm{~mm}$ is the lowest among the three schemes.

\subsubsection{Volume Fraction of Cavitation Phase}

Two kinds of cavitation mechanisms deserve an elucidation in the submerged water jet considered. One is the shear layer produced by the velocity difference between jet stream and ambient water; the other one is related to the flow patterns adjacent to the downstream end of the central body. Numerical results of cavitation are depicted in Figure 8 where the three cross sections are identical with those shown in Figure 7. It can be extrapolated from Figure 8 that a tongue-shape cavitation zone exists immediately downstream of the central body. In light of the velocity distributions shown in Figure 7, the end of the cavitation zone is in accordance with the position where the water jet reorganizes itself. At $s=0.0 \mathrm{~mm}$, the end section of the central body is parallel to the nozzle outlet section, thus the cavitation zone covers the longest stream wise distance among the three schemes.

In Figure 8, three-dimensional cavitation zones can be generated through rotating the sectional view around the jet axis by $360^{\circ}$. Although the maximum volume fraction of cavitation phase appears at the jet axis, the impingement effect exerted on the sample surfaceis inseparable from peripheral cavitation bubbles.

To relate the cavitation zone shape with jet pressure, a simulation for the scheme of $s=0.0 \mathrm{~mm}$ was performed at jet pressure of $20 \mathrm{MPa}$. And the results are shown in Figure 9. It is observable that axial length of the cavitation zone is increased accordingly and the tongue shape is well kept in this context. Through the comparison of Figure 8 with Figure 9, it is proved that cavitation effect is determined by dual factors, low-pressure zone after the central body and shear effect between jet stream and ambient water. And the former is comparatively influential.

\section{Impingement Experiment}

To gain a further insight into submerged water jet discharged from the central-body nozzle, an experiment was conducted with sandstone samples at jet pressure of $15 \mathrm{MPa}$. The nozzle corresponding to the scheme of $s=0.0$ $\mathrm{mm}$ was used in the experiment and a round nozzle with equivalent outlet diameter was applied to produce a submerged water jet for comparison. Mass weighting method was used and the mass of removed sandstone material was measured after the impingement.

For the two water jets subject respectively to the two nozzles, five samples with the same dimensions were tested at the same standoff distance of $3.0 \mathrm{~mm}$ and the same impingement period of ten seconds. The results are shown in Figure 10.

As shown in Figure 10, The overall mass of removed sandstone with the central-body nozzle is larger than that with the round nozzle. For the corresponding relation between jet pressure and velocity, the jet discharged from the central-body nozzle bears a large bulk velocity and a thin annulus jet layer, so the impingement capability is favorable relative to the round water jet. As the standoff distance is increased to $5.0 \mathrm{~mm}$, impingement effect signified by the mass of material removed is shown in Figure 11.

Compared with Figure 10, Figure 11 indicates that the discrepancy among the five cases is remarkable. With 


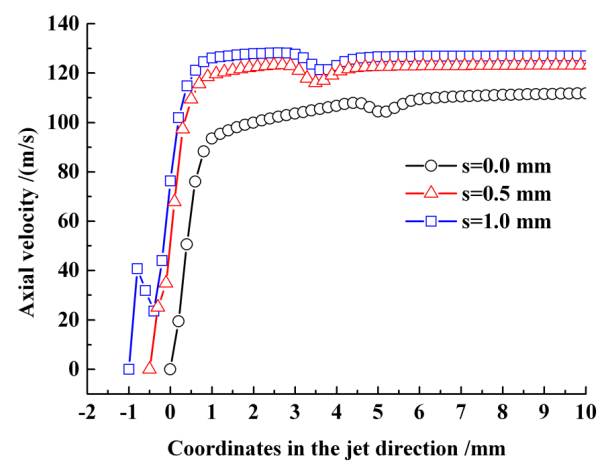

Figure 6. Velocity dissipation along the jet axis.

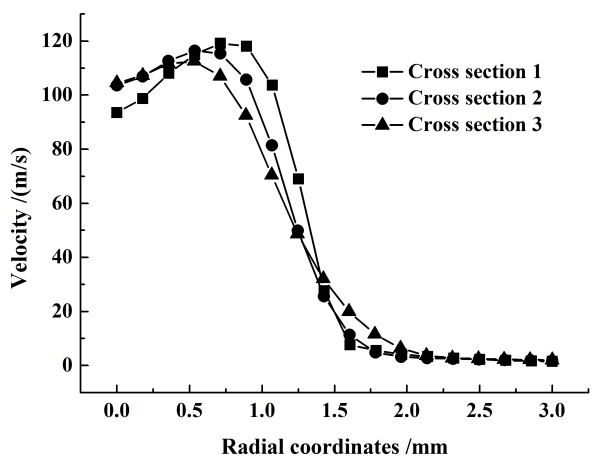

(a)

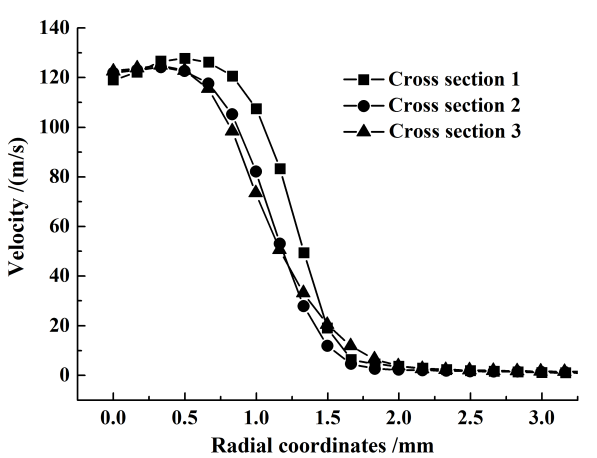

(b)

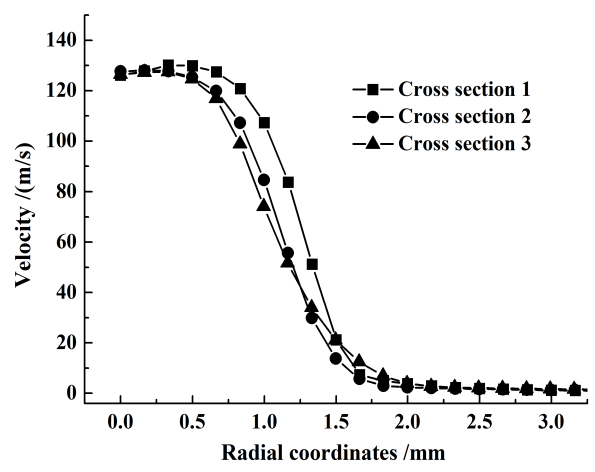

(c)

Figure 7. Velocity distributions on different transverse sections. (a) $s=0.0 \mathrm{~mm}$; (b) $s=0.5$ $\mathrm{mm}$; (c) $s=1.0 \mathrm{~mm}$

the central-body nozzle, a strong fluid-solid interaction is verified thereby. According to numerical results, the standoff distance of $5.0 \mathrm{~mm}$ corresponds to the front end of the cavitation tongue. Therefore it can be estimated that cavitation effect accelerates the erosion of sandstone material. Although the distance between the nozzle outlet and the target sample surface increases, the impingement effect remains almost unaltered. For the round water jet, energy dissipation with increased standoff distance has a significant influence on impingement effect, as evidenced in Figure 11.

\section{Concluding Remarks}

For submerged water jet discharged from the central-body nozzle, instantaneous variation of jet width is evident. For the scheme in which the end cross section of the central bodyis parallel to the nozzle outlet section, overall jet width is the largest but the jet width fluctuation is the slightest. Cavitation tongue exists in the wake flow immediately downstream of the central body. Stream wise length of cavitation tone is determined by both axial 


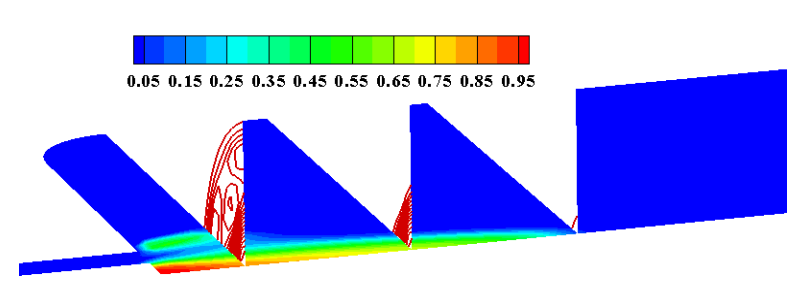

(a)

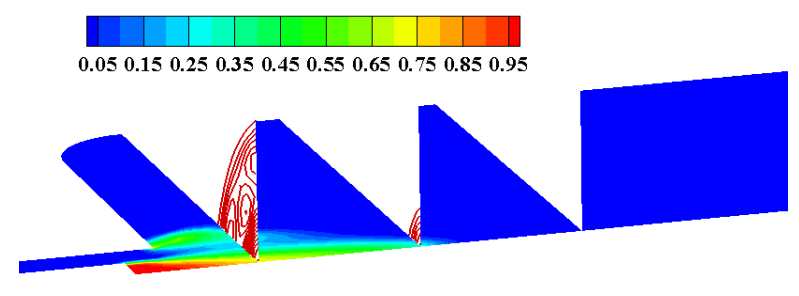

(b)

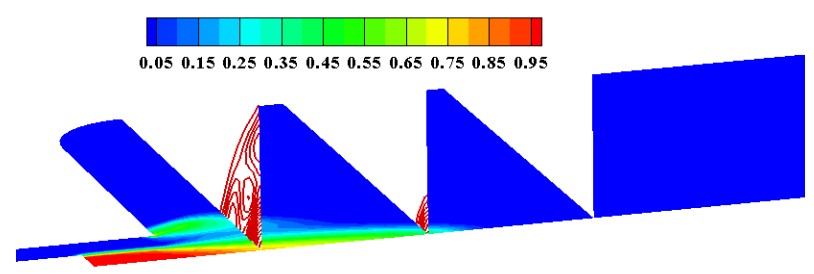

(c)

Figure 8. Volume fraction of cavitation phase at $15 \mathrm{MPa}$. (a) $s=0.0 \mathrm{~mm}$; (b) $s=0.5 \mathrm{~mm}$; (c) $s=1.0 \mathrm{~mm}$.

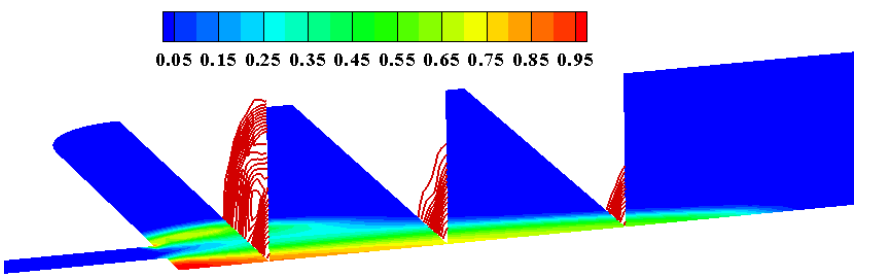

Figure 9. Volume fraction of cavitation phase at $20 \mathrm{MPa}$ associated with the scheme of $s=0.0 \mathrm{~mm}$.

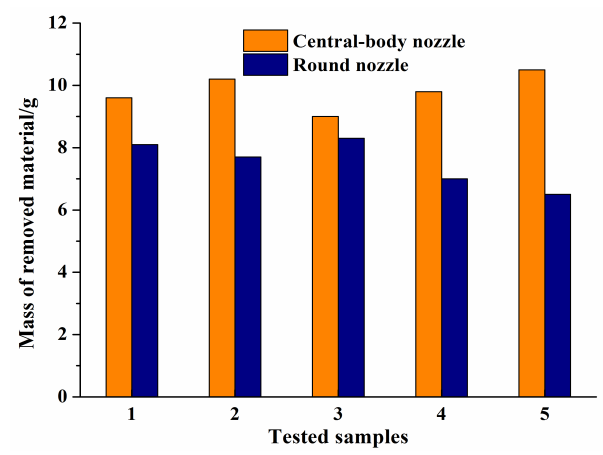

Figure 10. Mass of removed sandstone at standoff distance of $3.0 \mathrm{~mm}$.

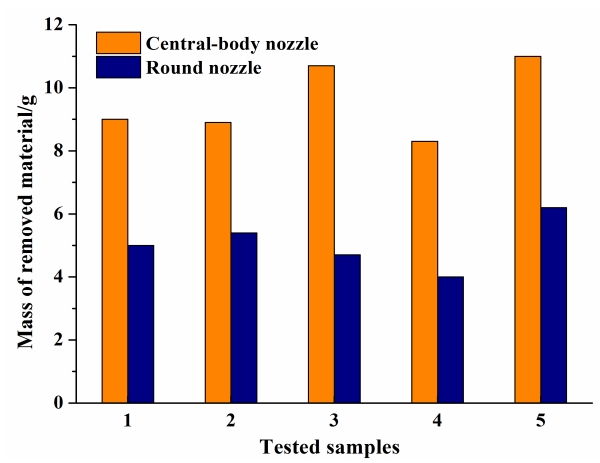

Figure 11. Mass of removed material at standoff distance of $5.0 \mathrm{~mm}$. 
position of the central body and jet pressure. At the same jet pressure, impingement effect is strong with the central-body nozzle, particularly as the target surface is at the front end of the cavitation zone. The mass of the material removed indicates evidently that cavitation reinforces impingement effect.

\section{Acknowledgements}

This study is financially supported by National Natural Science Foundation of China (Grant No. 51205171). The authors of this paper also would like to extend their gratitude to Postdoctoral Science Foundation of Jiangsu Province of China (Grant No. 1201026B).

\section{References}

[1] Summers, D.A. (1983) Consideration in the Comparison of Cavitating and Plain Water Jets. Proceedings of the 2nd US Water Jet Conference, Missouri, 24-26 May 1983, 178-183.

[2] Hocheng, H. and Weng, C.H. (2002) Hydraulic Erosion of Concrete by a Submerged Jet. Journal of Materials Engineering and Performance, 11, 256-261. http://dx.doi.org/10.1361/105994902770344033

[3] Iio, S., Takahashi, K., Haneda, Y. and Ikeda, T. (2008) Flow Visualization of Vortex Structure in a Pulsed Rectangular Jet. Journal of Visualization, 11, 125-132. http://dx.doi.org/10.1007/BF03181927

[4] Xiang, W.Y., Li, X.H. and Lu, Y.Y. (2009) Cavitation Capacity of Submerged Abrasive Water Jets. Journal of Chongqing University, 32, 299-302.

[5] Kang, C., Wang, W.F., Zhang, F. and Yang, M.G. (2010) Experiment Study of Free Fan Water Jet Flow by Using PDPA. Chinese Journal of Hydrodynamics (Series A), 25, 822-829.

[6] Hutli, E., Alteash, O., Raghisa, M.B., Nedeljković, M.S. and Ilić, V. (2013) Appearance of High Submerged Cavitating Jet: The Cavitation Phenomenon and Sono-Luminescence. Thermal Science, 17, 1151-1161.

[7] Shiau, B., Yang, C.L. and Tsai, B. (2007) Experimental Observations on the Submerged Discharge of Brine into Coastal Water in Flowing Current. Journal of Coastal Research, 50, 789-793.

[8] Kang, C., Zhang, F., Liu, D. and Yang, M.G. (2010) Statistical Characteristics in Water Jet Discharged from a CentralBody Nozzle. Proceedings of ASME FEDSM-ICNMM, Montreal, 1-5 August 2010, 137-143.

[9] Soyama, H., Yanauchi, Y. and Sato, K. (1996) High-Speed Observation of Ultrahigh-Speed Submerged Water Jets. Experimental Thermal and Fluid Science, 12, 411-416. http://dx.doi.org/10.1016/0894-1777(95)00124-7

[10] Kang, C., Zhang, F. and Yang, M.G. (2011) Experimental and Statistical Analysis of Water Jet Discharged from an Annular Nozzle. Journal of Experiments in Fluid Mechanics, 25, 7-12.

[11] Singhal, A.K., Athavale, M.M. and Li, H.Y. (2002) Mathematical Basis and Validation of the Full Cavitation Model. Journal of Fluids Engineering, 124, 617-624. http://dx.doi.org/10.1115/1.1486223 
Scientific Research Publishing (SCIRP) is one of the largest Open Access journal publishers. It is currently publishing more than 200 open access, online, peer-reviewed journals covering a wide range of academic disciplines. SCIRP serves the worldwide academic communities and contributes to the progress and application of science with its publication.

Other selected journals from SCIRP are listed as below. Submit your manuscript to us via either submit@scirp.org or Online Submission Portal.
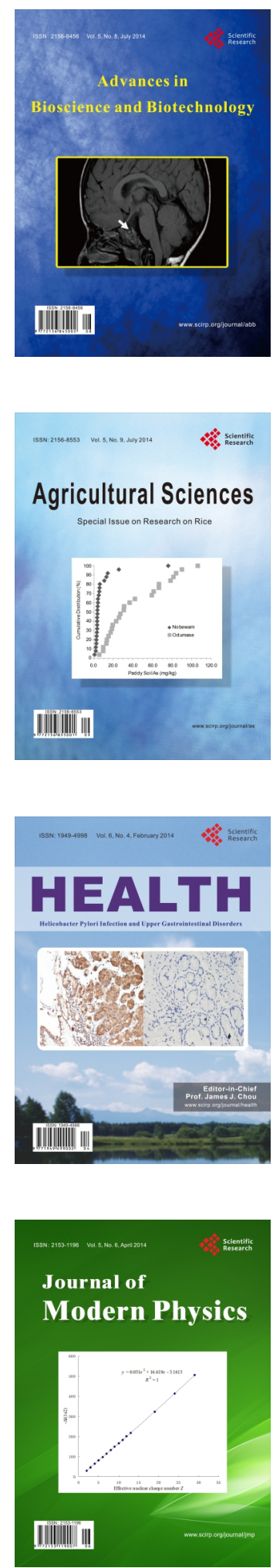
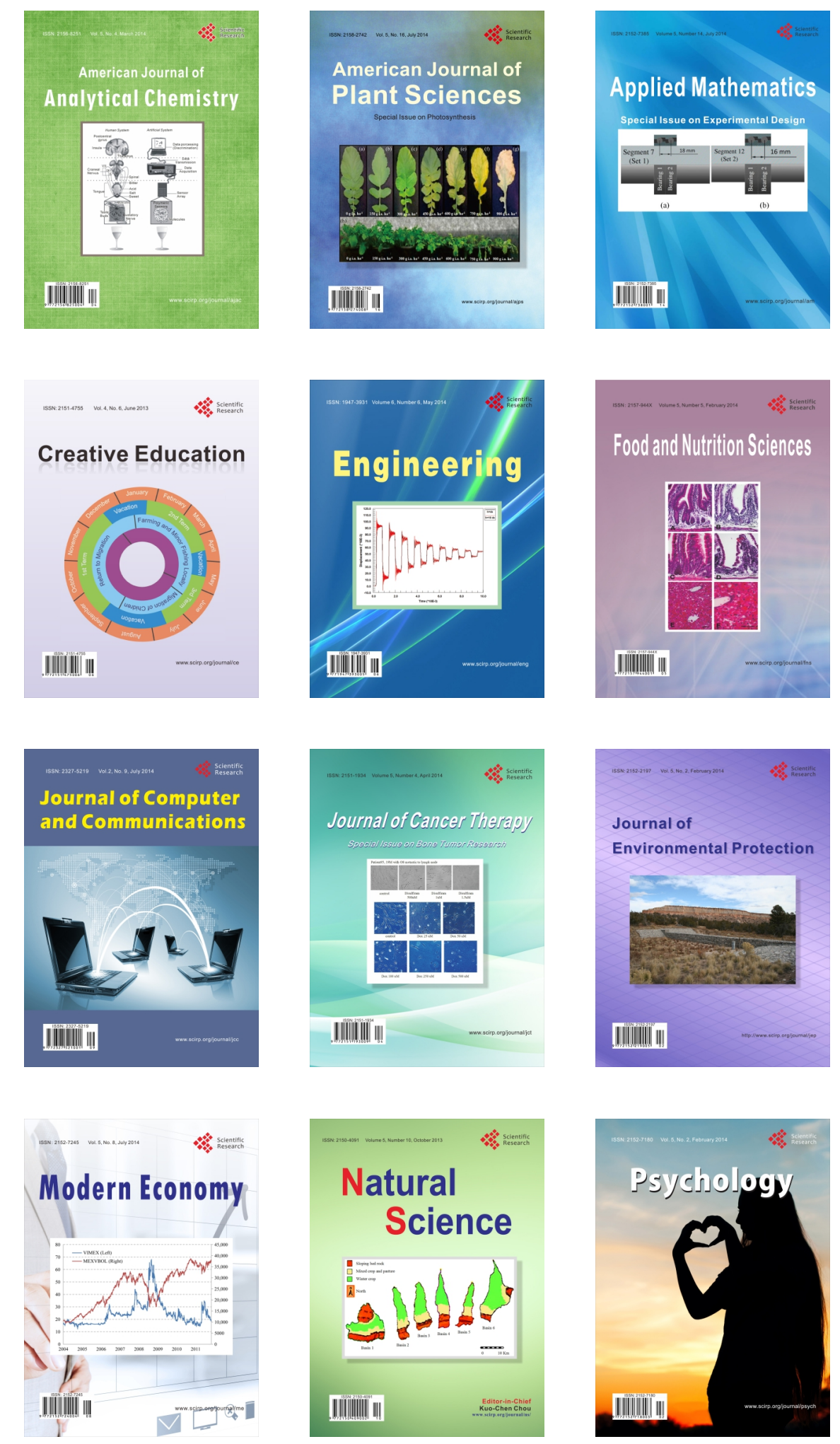